\title{
Mathematicians Take a Stand
}

\section{Douglas N. Arnold and Henry Cohn}

In an effort to keep Notices readers apprised of timely matters, we offer here articles presenting the two sides of the Elsevier boycott issue. Douglas Arnold and Henry Cohn write in favor of the boycott, while David Clark and Laura Hassink write on behalf of Elsevier. These two articles represent the views of the authors, and not those of the editors or the American Mathematical Society. This editor (SGK) is in fact the editor of an Elsevier journal. He takes no side in this discussion.

-Steven G. Krantz

Mathematicians care deeply about the mathematical literature. We devote much of our lives to learning from it, expanding it, and guaranteeing its quality. We depend on it for our livelihoods, and our contributions to it will be our intellectual legacy.

It has long been anticipated that technological advances will make the literature more affordable and accessible. Sadly, this potential is not being fully realized. The prices libraries pay for journals have been growing with no end in sight, even as the costs of publication and distribution have gone down, and many libraries are unable to maintain their subscriptions. ${ }^{1}$

The normal market mechanisms we count on to keep prices in check have failed for a variety of reasons. For example, mathematicians have a professional obligation to follow the relevant literature, which leads to inelastic pricing. This situation is particularly perverse because we provide the content, editorial services, and peer review free of charge, implicitly subsidized by our institutions. The journal publishers then turn to the same institutions and demand prices that seem unjustifiable.

Although the detailed situation is complex, the fundamental cause of this sad state of affairs is not hard to find. While libraries are being forced to cut acquisitions, a small number of commercial publishers have been making breathtaking profits year

Douglas N. Arnold is McKnight Presidential Professor of Mathematics at the University of Minnesota. His email address is arnold@umn. edu.

Henry Cohn is principal researcher at Microsoft Research New England and adjunct professor of mathematics at MIT. His email address is cohn@mi crosoft.com.

${ }^{1}$ For example, MIT's spending on serials increased by 426 percent over the period 1986-2009, while the number of serials purchased decreased by 16 percent, and the Consumer Price Index increased by only 96 percent.

DOI: http://dx.doi.org/10.1090/noti857 after year. The largest of these, Elsevier, made an adjusted operating profit of $\$ 1.12$ billion in 2010 on $\$ 3.14$ billion in revenue, for a profit margin of 36 percent, up from 35 percent in 2009 and 33 percent in 2008. ${ }^{2}$ Adding insult to injury, Elsevier has aggressively pushed bundling arrangements that result in libraries paying for journals they do not want and that obscure the actual costs. ${ }^{3}$ They have fought transparency of pricing, going so far as to seek a court injunction in an unsuccessful attempt to stop a state university from revealing the terms of their subscription contract. They have imposed unacceptable restrictions on dissemination by authors. And, while their best journals make important contributions to the mathematical literature, Elsevier also publishes many weaker journals, some of which have been caught in major lapses of peer review or ethical standards. These scandals have done harm to the integrity and reputation of mathematics.

This situation has been extensively analyzed many times before, including in the Notices. There have been some high-profile actions, such as mass resignations of entire Elsevier editorial boards over pricing concerns: the Journal of Logic Programming in 1999, the Journal of Algorithms in 2003, and Topology in 2006. These boards have done a valuable service for the community by founding replacement journals, but there has been little relief from the overall trend. As Timothy Gowers wrote in his blog in January, "It might seem inexplicable that this situation has been allowed to continue. After all, mathematicians (and other scientists) have been complaining about it for a long time. Why can't we just tell Elsevier that we no longer

\footnotetext{
${ }^{2}$ Reed Elsevier Annual Report 2010, SEC form 20-F (based on data from $p .25$ and average exchange rate from $p$. 6).

${ }^{3}$ T. Bergstrom, Librarians and the terrible fix: economics of the Big Deal, Serials 23 (2010), 77-82.
} 
Table 1: Summary information for six journals.

\begin{tabular}{lllrrrr}
\hline \hline Journal & Publisher & Metrics & Price & \$/art. & \$/page & \$/cite \\
\hline Annals of Mathematics & Princeton & 3.7/A* & $\$ 447$ & 5.39 & 0.12 & 0.06 \\
SIAM J. Appl. Math. & SIAM & $1.8 / A^{*}$ & $\$ 642$ & 5.95 & 0.27 & 0.13 \\
Journal of the AMS & AMS & $3.6 / A^{*}$ & $\$ 300$ & 9.09 & 0.24 & 0.13 \\
Advances in Mathematics & Elsevier & $1.6 / A^{*}$ & $\$ 3,899$ & 11.53 & 0.35 & 0.90 \\
Journal of Algebra & Elsevier & $0.7 / A^{*}$ & $\$ 6,944$ & 13.89 & 0.75 & 1.22 \\
Journal of Number Theory & Elsevier & $0.6 / \mathrm{B}$ & $\$ 2,745$ & 17.49 & 1.12 & 1.91 \\
\hline \hline
\end{tabular}

Metrics are the 2010 5-year impact factor from Journal Citation Reports and the 2010 rating by the Australian Research Council (based on expert opinion). A* = top-rated, B = "solid, though not outstanding".

Elsevier prices are the amounts actually paid by the University of Minnesota for electronic-only institutional subscriptions in 2012. The lowest prices we could find on the Elsevier website as of February 29 were $\$ 3,555.20, \$ 5,203$, and $\$ 2,226.40$. The Annals price is again the actual amount paid by UMN, which is slightly greater than the $\$ 435$ list price. The SIAM and AMS prices are the list prices, although UMN paid less because of institutional membership.

Columns 5-7 normalize by the most recent data available: the numbers of articles and pages published in 2011 and the number of citations to the journal made in 2010 (as reported in Journal Citation Reports).

wish to publish with them?" Gowers then revealed that he had been quietly boycotting Elsevier for years, and he suggested it would be valuable to create a website where like-minded researchers could publicly declare their unwillingness to contribute to Elsevier journals.

Within days, Tyler Neylon responded to this need by creating http://thecostofknowledge. com More than 2,000 people signed on in the first week, and participation has grown steadily since then, to over 8,000 as of early March. Each participant chooses whether to refrain from publishing papers in, refereeing for, or editing Elsevier journals. The boycott is ongoing, and it holds the promise of sparking real change. We urge you to consider adding your voice.

The boycott is a true grassroots movement. No individual or group is in charge, beyond Gowers's symbolic position as the first boycotter. However, a group of thirty-four mathematicians ${ }^{4}$ (including Gowers and the authors of the present article) issued their best attempt at a consensus statement of purpose for the boycott. It is available online, ${ }^{5}$ and we highly recommend it for reading. For reasons

\footnotetext{
${ }^{4}$ Scott Aaronson, Douglas N. Arnold, Artur Avila, John Baez, Folkmar Bornemann, Danny Calegari, Henry Cohn, Ingrid Daubechies, Jordan Ellenberg, Matthew Emerton, Marie Farge, David Gabai, Timothy Gowers, Ben Green, Martin Grötschel, Michael Harris, Frédéric Hélein, Rob Kirby, Vincent Lafforgue, Gregory F. Lawler, Randall J. LeVeque, László Lovász, Peter J. Olver, Olof Sisask, Terence Tao, Richard Taylor, Bernard Teissier, Burt Totaro, Lloyd N. Trefethen, Takashi Tsuboi, Marie-France Vignéras, Wendelin Werner, Amie Wilkinson, and Günter M. Ziegler.

${ }^{5}$ See http://umn . edu/ arnold/sop.pdf or the March 2012 London Mathematical Society Newsletter.
}

of space, we will not cover every aspect of that statement here.

Before we proceed, we must address two pressing questions about the boycott. First, why is a boycott appropriate? After all, Elsevier employs many reasonable and thoughtful people, and many mathematicians volunteer their services, helping to produce journals of real value. Isn't a boycott overly confrontational? Could one not take a more collaborative approach? Unfortunately, such approaches have been tried time and again without success. Fifteen years of reasoned discussions have failed to sway Elsevier. ${ }^{6}$ Elsevier's leadership seems to be driven only by their fiduciary responsibility to maximize profit for their shareholders. The one hope we see for change is to demonstrate that their business depends on us and that we will not cooperate with them unless they earn our respect and goodwill.

Second, why is the focus solely on Elsevier? Some of the problems we discuss are common among large commercial publishers, and indeed we hope the boycott will help spur changes in the whole industry. But we must start somewhere, and we believe it is more effective to focus on one publisher whose behavior has been particularly

\footnotetext{
${ }^{6}$ R. Kirby, Comparative prices of math journals, 1997, http://math.berkeley.edu/ kirby/journals.htm7; J. Birman, Scientific publishing: A mathematician's viewpoint, Notices of the AMS 47 (2000), 770-774; R. Kirby, Fleeced?, Notices of the AMS 51 (2004), 181; W. Neumann, What we can do about journal pricing, 2005, http://www. math. columbia.edu/ neumann/ journa $1 . \mathrm{htm} 7 ;$ D. N. Arnold, Integrity under attack: The state of scholarly publishing, SIAM News 42 (2009), 2-3; P. Olver, Journals in flux, Notices of the AMS 58 (2011), 1124-1126.
} 
Table 2: Historical prices per page in constant 2012 dollars.

\begin{tabular}{lcccccccc}
\hline \hline Journal & 1994 & 1997 & 2000 & 2003 & 2006 & 2009 & 2010 & 2011 \\
\hline Annals of Mathematics & 0.19 & 0.20 & 0.14 & 0.15 & 0.13 & 0.13 & 0.09 & 0.10 \\
SIAM J. Appl. Math. & 0.20 & 0.24 & 0.23 & 0.25 & 0.27 & 0.24 & 0.18 & 0.27 \\
Journal of the AMS & 0.22 & 0.26 & 0.27 & 0.29 & 0.30 & 0.27 & 0.25 & 0.24 \\
Advances in Mathematics & 0.65 & 0.74 & 0.95 & 1.01 & 0.55 & 0.61 & 0.44 & 0.33 \\
Journal of Algebra & 0.36 & 0.43 & 0.50 & 0.73 & 0.60 & 0.77 & 0.92 & 0.66 \\
Journal of Number Theory & 0.57 & 0.67 & 0.98 & 1.01 & 1.04 & 0.86 & 0.95 & 1.05 \\
\hline \hline
\end{tabular}

Prices are from the AMS journal price survey http://www . ams .org/membership/ mem-journa7-survey, adjusted using the Consumer Price Index.

egregious than to directly confront an entire industry at once. Many of the successful boycotts in history took the same tack.

\section{Journal Pricing}

Table 1 exhibits prices for three of Elsevier's mathematics journals: Advances in Mathematics, the Journal of Algebra, and the Journal of Number Theory. For comparison, the table includes three more affordable journals.

The Annals of Mathematics, published by the Princeton math department and IAS, provides exceptional quality at a rock-bottom price that just covers costs. The other two are highly regarded journals published by the Society for Industrial and Applied Mathematics (SIAM) and by the American Mathematical Society (AMS). Both of these organizations make a profit on their journal publishing operations, which helps to subsidize their other activities. For example, in 2011 SIAM's journal publication costs, including overhead, were 89 percent of their subscription revenues, resulting in an 11 percent profit margin.

Elsevier's recent pricing changes, apparently in response to the boycott, have at times led to multiple conflicting prices on their website. We have listed the prices actually paid by the University of Minnesota in 2012, but the notes after the table indicate the lowest prices we found offered on the Web. We made no attempt to select the highestpriced Elsevier journals, and in fact Advances in Mathematics is among the most affordable. For comparison, the 2011 prices per page of the thirtysix Elsevier journals listed in the AMS journal price survey ranged from $\$ 0.33$ (Advances in Mathemat ics) to $\$ 4.05$ (Mathematical Social Sciences), with a mean of $\$ 1.35$ and a median of $\$ 0.96$.

As shown in the table, the prices of the SIAM and AMS journals are within a factor of two of that of the Annals, with differences depending on whether one normalizes the raw journal price by number of articles, pages, or citations. But the Elsevier prices are a different story. The price per page of the Journal of Algebra, for example, is triple that of the society journals and six times that of the Annals, and the Journal of Number Theory is 50 percent more expensive yet.

Moreover, as demonstrated in Table 2, this problem has grown over time. The inflationadjusted prices per page of the Journals of Algebra and Number Theory increased by more than 80 percent between 1994 and 2011, compared with much smaller increases for the society journals and a decrease for the Annals. It is noteworthy that the recent prices of Advances in Mathematics, while still high, have come closer to the prices of the society journals. This supports our belief that Elsevier could offer substantially lower prices and still make a reasonable profit.

We do not mean to suggest that publishing is cheap in the electronic age. True, electronic distribution is very cheap: the arXiv requires just $\$ 7$ per submission, or 1.4 cents per download, in funding. ${ }^{7}$ But journal publishing involves significant additional costs, such as IT infrastructure, administrative support, oversight, sales, copyediting, typesetting, archiving, etc. Many of these costs scale roughly with the number of published pages, and some of them benefit from economies of scale (so large publishers like Elsevier should, if anything, achieve lower costs).

Of course, journals are not all the same. A lowcirculation journal may need to command a higher price per page to stay afloat. The community might find some such journals too expensive to support, but one viewed as worthy of support might reasonably charge a higher price until more libraries subscribe. Another journal might have extraordinary expenses, for example from translation. But these factors do not apply to the cases we have considered or to many other Elsevier journals.

We see no good reason to pay much more for Elsevier journals than for journals that earn mathematical societies a tidy profit. Even the price

$\sqrt[7 \text { http://arXiv.org/help/support/faq }]{ }$ 
targets for mathematics journals that Elsevier announced in response to the boycott ${ }^{8}-\$ 0.50$ to $\$ 0.60$ per page-would leave their journals costing twice as much as the comparison journals in Table 1. Elsevier's prices have become far out of proportion and have a way to go to return to reasonable.

\section{What's the Big Deal about Bundling?}

Bundling refers to grouping together collections of journals and selling access as a single product, discounted from list price. Elsevier commonly negotiates bundles that include all the journals to which the library has recently subscribed. The bundles may also include access to nearly all of Elsevier's roughly 2,000 journals. Librarians have termed enormous bundles "the big deal".

While there is nothing wrong with offering quantity discounts,${ }^{9}$ it is the way in which Elsevier and other large publishers have implemented bundling that is objectionable. They have turned it into a powerful tool for subverting the market forces that would keep prices in check. The then director of Harvard's library summarized it thus: "Elsevier is among a handful of journal publishers whose commercial bundling practices are squeezing library budgets. Their licensing programs require libraries to maintain large, fixed levels of expenditure, without the ability to cancel unneeded subscriptions." 10

Let us see how this works. While Elsevier has gone to great lengths to keep the details of their bundle contracts secret, some have come to light, thanks to open records laws. ${ }^{11}$ Judging by the contracts we have seen and librarians we have consulted, it works essentially as follows.

The university commits to subscribing to the journals it currently receives at a negotiated total price that is typically around the same as they were previously paying and to continuing to subscribe to them for a period of three to five years with annual price increases. Elsevier has called this the "Complete Collection", and it is a large expense. For example, for the University of Minnesota in 2006 it came to $\$ 1.8$ million (about 18 percent of their total serials budget), and for the University of Michigan in 2007 it was \$1.9 million. In both cases, 5 percent yearly price increases were built into the contracts, although the actual rate of inflation for the contract periods was only about 2 percent

${ }^{8}$ D. Clark and L. Hassink, A letter to the mathematics community, February 27, 2012, http:// www.e1sevier.com/wps/find/P11.cws_home/ lettertothecommunity.

${ }^{9}$ For example, Mathematical Sciences Publishers offers a bundle of six mathematics journals at a 31 percent discount, bringing their price down to $\$ 0.08$ per page. 10 http://hu1 . harvard. edu/news/2004_0101.htm7.

${ }^{11}$ T. Bergstrom, P. Courant, and R. P. McAfee, Big Deal Contract Project. per year. Cancellation of titles in the Complete Collection is restricted, which makes it difficult or impossible to cut back on the expenditure.

For an additional fee Elsevier offers their "Freedom Collection", which adds deeply discounted access to nearly all of the Elsevier journals to which the library had not chosen to subscribe. This option cost the University of Michigan about $\$ 19,000$ more in 2007, inflating 5 percent a year thereafter. The University of Minnesota elected against it.

Although prices increase quickly inside the bundle, list prices can increase even more quickly, so a university that decides not to renew its bundle may face a steep price increase to hold onto the journals it wants. Because of bundling, ever larger portions of library budgets are locked into Elsevier contracts, budgetary pressures force the cancellation of titles from smaller publishers, and funds for new subscriptions disappear. Furthermore, bundling leads to a lack of clarity on pricing. The discounts on the additional journals in the Freedom Collection can sound impressive, but it is the pricing of the primary subscriptions that drains library budgets.

The constraints imposed by bundles have led some universities to conclude that even paying exorbitant prices for the journals they choose is a better deal. Harvard, MIT, the University of Minnesota, and others have now gone this route. However, many academic libraries remain tied to the big deal.

Price disclosure is necessary for a well-functioning market with competitive pricing, so the lack of transparency in bundling contracts is particularly troubling. As an Elsevier vice president wrote in support of Elsevier's 2009 lawsuit enjoining Washington State University from revealing the prices of their subscriptions, "Elsevier representatives apply pricing formulae and methods which are not generally known (to our competitors or potential customers)" and "disclosure could disadvantage Elsevier in that, if its pricing to customer $\mathrm{X}$ was known to customers $\mathrm{Y}$ and $\mathrm{Z}$, the latter could demand the same pricing". ${ }^{12}$ Elsevier may indeed profit from keeping $\mathrm{Y}$ and $\mathrm{Z}$ in the dark, but the academic community values sunlight. Without transparency of subscription contracts and costs, the community will remain skeptical of Elsevier's pricing, whatever changes they make to list prices.

\section{Posting Policies}

Gowers's suggestion of an Elsevier boycott struck a chord in many researchers. Besides pricing and bundling, there are other issues that have contributed to so many researchers' readiness to abandon Elsevier. One of these is Elsevier's policies concerning $\overline{12}$ http://www.econ.ucsb.edu/ tedb/Journals/
WSUCourtCase/ElsevierStatementbySalesChief.
pdf 
dissemination. Thanks to the Internet, authors have additional ways of disseminating their work besides the printed journal and journal website. For example, it has become common practice for authors to post a finalized version of their manuscript to a repository such as the arXiv for open dissemination, as allowed by many publishers. ${ }^{13}$ Elsevier's actions suggest that they view this development primarily as a threat to their profits, not as an opportunity to advance mathematics or increase their authors' readership. In short, their interests are not aligned with ours.

Elsevier's policies are complex and difficult to understand. In the words of the scholarly communications officer at Duke University, "It seems clear that the intent of these statements, policies and contracts is not to clarify the authors' obligations so much as it is to confuse and intimidate them." 14 Their posting policy ${ }^{15}$ specifically prohibits posting an "accepted author manuscript"-the author's own version of a manuscript that has been accepted for publication - on an email list, a subject repository, or even the author's own institutional repository if the institution has a posting mandate. The last is not a typo: if your institution mandates posting the accepted author manuscript in its repository, then Elsevier stipulates that you may not, although they permit such posting when there is no mandate!

Fortunately, since hearing complaints from the boycotters about their posting policy, Elsevier has introduced an exception to allow posting to the arXiv. However, that is not enough. There are other noncommercial subject repositories that are important to segments of the community (Optimization Online, the Cryptology ePrint Archive, etc.), and more will undoubtedly be created in the future. Elsevier should allow authors to post accepted manuscripts to any such repository, as well as to university repositories, regardless of whether there is a posting mandate. Furthermore, this right should be guaranteed by the publishing agreement, not just by a posting policy that is subject to change at any time.

\section{Ethics and Peer Review}

Another source of frustration with Elsevier is their history of lapses in peer review and ethics. The case of the journal Chaos, Solitons \& Fractals (CS\&F) has become widely known. This journal published 273 papers by its own editor in chief over eighteen

\footnotetext{
${ }^{13} \mathrm{~K}$. Fowler, Do mathematicians get the author rights they want?, Notices of the AMS 59 (2012), 436-438.

${ }^{14}$ K. Smith, What a mess!, Scholarly Communications@ Duke, July 7, 2011, http://blogs. 1ibrary.duke.edu/ scholcomm/2011/07/07/what-a-mess/.

15 http://www.e1sevier.com/wps/find/authorsview. authors/postingpolicy, accessed March 3, 2012.
}

years, 57 of them in a single year. Suspicions that these papers were not subject to peer review are corroborated by the editor's declaration that "senior people are above this childish, vain practice of peer review." 16 Elsevier owes the community an explanation for this and other fiascos. Was there no oversight in place? Have changes been made so this will not happen again? What about the other papers in CS\&F? Are there records of peer review? Will any papers that were not peer reviewed be retracted or otherwise flagged? The current situation leaves the literature in a bad state and compromises the position of authors who submitted manuscripts for peer review in good faith. If Elsevier wants to place this issue behind them, they need to deal with it thoroughly, forthrightly, and transparently.

In another notorious case, for five years Elsevier "published a series of sponsored article compilation publications, on behalf of pharmaceutical clients, that were made to look like journals and lacked the proper disclosures."17

There are other incidents in which peer review has failed at Elsevier journals, sometimes in spectacular fashion. ${ }^{18}$ For many of us, these call into question Elsevier's ability to meet the standards of quality and ethics we require if we are to collaborate with them.

\section{Initial Responses to the Boycott}

On February 27, Elsevier publicly withdrew its support for the Research Works Act, which would have prohibited open access mandates for governmentfunded research. The bill was declared dead by its sponsors in Congress on the very same day. This victory confirmed the boycott's success in delivering a message where we were never able to get through before.

Further confirmation came that day in an open letter from Elsevier senior vice presidents David Clark and Laura Hassink to the mathematics community. ${ }^{8}$ Besides reporting the about-face on the Research Works Act, they announced the target price for "core mathematics titles" that we discussed above. They also stated, correctly, that it would be necessary to address concerns about "large discounted agreements" (bundling) and said that this will come.

\footnotetext{
${ }^{16}$ C. Whyte, El Naschie questions journalist in Nature libel trial, updated November 16, 2011, http://www. newscientist.com/article/dn21169.

${ }^{17}$ Statement from Michael Hansen, CEO of Elsevier's Health Sciences Division, regarding Australiabased sponsored journal practices between 2000 and 2005, May 7, 2009, http://www.e1sevier. com/wps/find/authored_newsitem.cws_home/ companynews05_01203.

18 http://umn.edu/ arnold/reasons.htm1
} 
Finally, Clark and Hassink announced that free access has been granted to the archives of fourteen core mathematics journals for the years from 1995 through four years before the present day. Access to back issues is indeed critical, and we strongly believe that all research papers should be made freely available long before copyright expires. The shorter the delay the better, of course, but we consider four years a defensible choice, compatible with the subscription model for journal publishing. The AMS's experience with a five-year window shows that such a move is financially viable. We hope that Elsevier's announcement is just the first step and that expansion to the full set of mathematical journals and the period before 1995 will be announced soon. ${ }^{19}$ We also hope that this is not just a temporary measure. A binding commitment not to revoke access in the future would be reassuring on that point.

\section{Moving Forward}

While the mathematical literature itself is a treasure, the current system of scholarly publishing is badly broken. Elsevier is the largest and, in our view, the most egregious example of what is wrong. We hope many readers will agree with us that by

${ }^{19}$ All three journals discussed here began publishing in the 1960s. The issues before 1995 are currently available from Elsevier online but remain behind their paywall. choosing to withdraw our cooperation from Elsevier, we are sending a valuable message to them and to the scholarly publishing industry more broadly. Please consider joining the movement at http://thecostofknowledge.com

What is our vision for the future? The mathematical community needs a period of experimentation and healthy competition, in which a variety of publishing models can flourish and develop. Possibilities include various approaches to open access publishing, ${ }^{20}$ refereed journals tightly integrated with the arXiv or similar servers, increased reliance on nonprofit publishers, hybrid models in which community-owned journals subcontract their operations to commercial publishers, commercially owned journals with reasonable prices and policies, etc. It is too early to predict the mix of models that will emerge as the most successful. However, any publisher that wants to be part of this mix must convince the community that they oversee peer review with integrity, that they aid dissemination rather than hinder it, and that they work to make high-quality mathematical literature widely available at a reasonable price.

Let's work together to foster good practices and build better models. The future of mathematics publishing is in our hands.

${ }^{20}$ For example, based on publication charges or on sponsoring consortia such as SCOAP http://scoap3.org.

\section{Elsevier's Response to the Mathematics Community}

\section{Laura Hassink and David Clark}

During the last months we have spoken to many people in the community about the move by Timothy Gowers and some colleagues to declare their wish not to work with Elsevier and the subsequent boycott movement.

At the end of this article we summarize how we are responding to the feedback from the community and the very specific steps that we are taking. But we would first like to address the concerns raised and some of the arguments.

We are the leading journal publisher in scientific publishing and so will attract criticism that is

Laura Hassink is Senior Vice President, Publishing, Elsevier. Her email address is 1. hassink@e1sevi er. com.

David Clark is Senior Vice President, Publishing, Elsevier. His email address is david. clark@e1sevier.com.

DOI: http://dx.doi.org/10.1090/noti853 directed at publishing as a whole. While we may disagree with much that has been said, we do recognize that Elsevier has not done a good job communicating what we do and how we support both the peer-review process and the dissemination of work. In particular, we have left authors, editors, reviewers, and board members with the impression that we are focussed on restricting access rather than making their research as widely available as possible.

Helping editors, authors, reviewers, and board members to work easily on journals is central to us. We have systems in place to make it easier for editors to run large journals, some of which are dealing with thousands of submissions each yearsomething which most smaller publishers are not equipped to do. There will, of course, be people 